Research Article

\title{
Fire Resistance of Composite Beams with Restrained Superposed Slabs
}

\author{
Junli Lyu (i), ${ }^{1,2}$ Qichao Chen, ${ }^{1}$ Huizhong Xue, ${ }^{1,2}$ Yongyuan Cai, ${ }^{1}$ Jingjing Lyu, ${ }^{1}$ \\ and Shengnan Zhou ${ }^{1}$ \\ ${ }^{1}$ School of Civil Engineering, Shandong Jianzhu University, Jinan 250101, China \\ ${ }^{2}$ Key Lab of Building Structural Retrofitting and Underground Space Engineering (Shandong Jianzhu University), \\ Ministry of Education, Jinan 250101, China
}

Correspondence should be addressed to Junli Lyu; 1j11978@163.com

Received 28 March 2020; Revised 31 May 2020; Accepted 22 June 2020; Published 10 July 2020

Academic Editor: María Criado

Copyright (c) 2020 Junli Lyu et al. This is an open access article distributed under the Creative Commons Attribution License, which permits unrestricted use, distribution, and reproduction in any medium, provided the original work is properly cited.

To investigate the fire resistance of composite beams with restrained superposed slabs, three specimens were tested under uniformly distributed loads in a furnace. The effects of the thickness of the postcast top layer in superposed slabs and the spacing of shear studs on the structural behaviours of composite beams under fire were further examined. During the tests, the temperature distributions of the superposed slabs and steel beams as well as the displacements at their key positions were recorded and analysed. It was found that the temperature of the concrete superposed slabs decreased long their heights from the bottom. The most drastic change of the temperature along the slab cross section was found in the region with a distance of $40 \mathrm{~mm}$ to the slab bottom. The concrete superposed slabs could impose restraints to the steel beams due to their incompatible deformations. Cracks were developed on the top surfaces of the specimens and the superposing interfaces between the precast slabs and postcast top layers were not broken. Through the comparisons of different specimens, the spacing of shear studs could have a significant effect on the fire resistance of composite beams, especially for their deformation recovery capacities. In contrast, the effect of the thickness of the postcast top layers was negligible. ABAQUS was employed to simulate the temperature fields and deformation behaviours of composite beam specimens based on a sequenced thermomechanical coupling analysis. The numerical results agreed well with the experiment data, which validated the developed numerical model.

\section{Introduction}

Steel-concrete composite beams are composed of two main components including steel beams and concrete slabs. Shear connectors/studs are commonly used to establish a reliable connection between the two components to allow their coworking. The composite beams have a broad application in residential and industrial buildings using prefabricating and assembling construction techniques. Considering that the fire disaster is one of the major threats for buildings, the research on the fire resistance of steel-concrete composite beams is timely required. Extensive research has been conducted on the fire resistance of two traditional types of composite beams, including the composite beams with profiled steel sheet and the composite beams with flat slabs.
The British Cardington BRE Laboratory $[1,2]$ completed a series of fire tests on the composite beams with profiled steel sheet. The results showed that the catenary action could be developed if adequate horizontal restraints were provided for the composite beams. Mirza and Uy [3] studied the influences of shear connectors on the fire resistance of composite beams through numerical studies using ABAQUS finite element software. It was found that the shear connectors slightly affected the structural performance of the composite beams with profiled steel sheet, whereas the composite beams with flat slabs could fail due to the rupture of shear connectors. However, other researchers [4-7] showed that the steel sheet could still detach from the steel beam in fire tests given that the shear studs were properly installed, leading to reduced load-carrying and deformation 
capacities. Moreover, an enhanced fire resistance could be achieved if the composite beams with profiled steel sheet were longitudinally restrained. Similarly, theoretical analysis [8] also showed that the restraints at the beam ends could also improve the fire resistance of composite beams with flat slabs.

The influence of different types of profiled steel sheet on the fire resistance of composite beams has also been examined [9] and results showed that the contribution of the profiled steel sheet could be neglected for flexural strength calculation. Lyu et al. [10-13] carried out fire tests on composite beams with flat slabs and found that the steel beam and the concrete slab could behave together with a better structural performance if a sufficient amount of shear connectors were arranged. In addition, the catenary action was not observed as only small deformations of composite beams were developed in the fire tests. From the existing studies, it is shown that the composite beams with different types of slabs behave distinctively in fire tests and the restrained composite beams exhibit a better fire resistance. Moreover, numerical analysis using finite element software is an effective approach to investigate the structural behaviours of composite beams under fire.

The composite beams with superposed slabs are a new type of structure member and consist of steel beams and concrete superposed slabs. Superposed slabs are different from the traditional concrete slabs as they are composed of a base layer of precast slabs and a top layer of postcast concrete. In this paper, the structural behaviours of three composite beams with restrained superposed slabs under fire are examined through experimental studies and numerical simulations.

\section{Experimental Program}

2.1. Specimen Design. Three specimens of composite beams with superposed slabs (SCB-1-3), consisting of a steel beam, concrete superposed slabs, and shear studs, were designed and fabricated according to relevant engineering standards. The total length of the composite beams was $4,300 \mathrm{~mm}$, and the width of the flanges was $1,625 \mathrm{~mm}$. The concrete superposed slabs were composed of a $60 \mathrm{~mm}$ thick precast base layer and a postcast top layer. The nominal concrete grade for both layers was C30. A two-layer configuration of rebars running in the two orthogonal directions was used as the main reinforcement in the superposed slabs. The spacings for the bottom and top rebars were $150 \mathrm{~mm}$ and $200 \mathrm{~mm}$, respectively. In addition, truss rebars were also arranged in the superposed slabs. The I-section beams were manufactured using Q235B hot-rolled steel with nominal dimensions of HN $250 \mathrm{~mm} \times 125 \mathrm{~mm} \times 6 \mathrm{~mm} \times 9 \mathrm{~mm}$. The nominal diameter of shear studs was $16 \mathrm{~mm}$. The dimensions and reinforcement details of a typical specimen are shown in Figure 1. Table 1 lists the thickness of the postcast top layers in the superposed slabs and the spacing of shear studs which were the main parameters examined in this study.
2.2. Material Properties. Given the construction requirements, the superposed slabs were manufactured in two steps. In the first step, the precast slabs were fabricated and set in place, after which the concrete of the postcast top layer was poured. Along with the fabrication of the specimens, three sets of standard concrete cubes with a nominal dimension of $150 \mathrm{~mm}$ were produced and cured under the same temperature and moisture conditions. Material property tests of unfired concrete and steel were conducted according to the Chinese standards GB/T 50081-2002 [14] and GB/T 228.1-2010 [15], respectively. The tested material properties of concrete and steel are given in Tables 2 and 3 , respectively. The material properties of shear studs were provided by the manufacturer.

2.3. Boundary Conditions. The tests were conducted in the Fire Laboratory of Shandong Jianzhu University. The furnace was modified based on the test requirements and allowed two specimens to be tested at the same time. To restrain the specimens, a reinforced concrete base beam and two steel columns (Figure 2(a)) were fabricated and assembled. During the fire tests, they were covered by fireresistant mineral wool. The steel columns were $2,800 \mathrm{~mm}$ high and fixed to the based beam through steel studs. These columns were made of Q235B steel and their sectional dimensions were HN $200 \mathrm{~mm} \times 200 \mathrm{~mm} \times 8 \mathrm{~mm} \times 12 \mathrm{~mm}$. The specimens were fully fixed to the steel columns through M22 friction high-strength bolts and steel end plates that had dimensions of $210 \mathrm{~mm} \times 160 \mathrm{~mm} \times 10 \mathrm{~mm}$ (Figure 2(b)). The test setup and the composite beam specimen ready for testing are shown in Figures 2(c) and 2(d), respectively.

2.4. Measurements. The temperature distribution and displacements of the composite beam were measured during the fire tests. The temperatures were measured at seven locations (A-C and E-H) of the specimens. Specifically, the thermocouples at the positions $\mathrm{A}-\mathrm{C}$ and $\mathrm{H}$ monitored the temperatures of concrete and rebar while the thermocouples at the positions $\mathrm{E}-\mathrm{G}$ measured the temperatures of concrete and steel beams. For the concrete, thermocouples were arranged with a $20 \mathrm{~mm}$ spacing in the slab thickness direction. Moreover, temperatures were measured for top and bottom layers of rebars, top and bottom flanges of steel beams, and the web of steel beams. The measurement position details are shown in Figure 3.

The displacements of the composite beam specimens were measured using five linear variable differential transformers (LVDTs) arranged at selected positions (D1-D5) shown in Figure 4.

2.5. Loading Scheme. In the test, two layers of iron blocks were placed on the top surface of the specimens to simulate a uniformly distributed load (UDL) of $3.5 \mathrm{kN} / \mathrm{m}^{2}$. Figure 5 shows the layout of the iron blocks. After the UDL was 


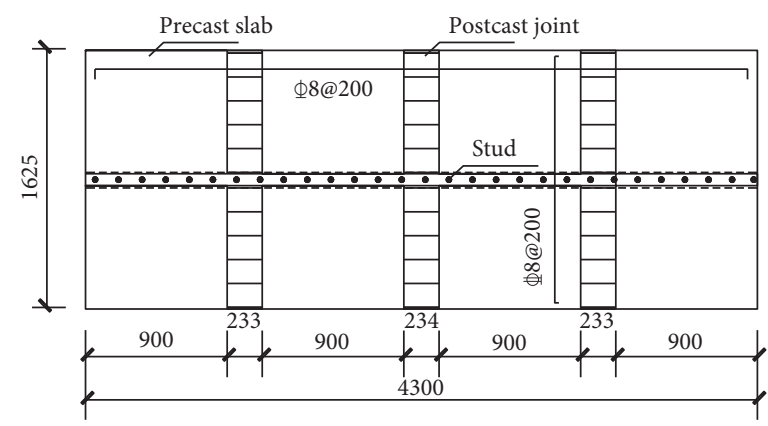

(a)

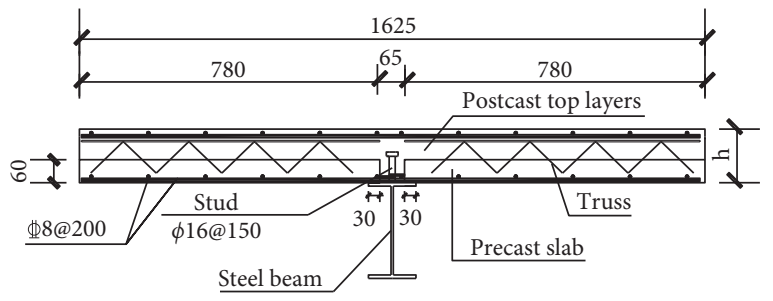

(b)

FIgURe 1: Specimen details: (a) plan view and (b) sectional view (unit: $\mathrm{mm}$ ).

TABLE 1: Varied parameters of tested specimens (unit: $\mathrm{mm}$ ).

\begin{tabular}{lcc}
\hline Specimen & Thickness of postcast top layer & Shear studs spacing \\
\hline SCB-1 & 80 & 150 \\
SCB-2 & 60 & 150 \\
SCB-3 & 80 & 200 \\
\hline
\end{tabular}

TABLe 2: Material properties of the unfired concrete.

\begin{tabular}{lccc}
\hline Concrete parts & Design strength & $f_{\text {ck }}(\mathrm{MPa})$ & $f_{\text {tk }}(\mathrm{MPa})$ \\
\hline The precast slab & C30 & 31.13 & 2.39 \\
The postcast top layers & C30 & 46.70 & 3.67 \\
\hline
\end{tabular}

TABLE 3: Material properties of the unfired steel.

\begin{tabular}{|c|c|c|c|c|c|}
\hline Steel parts & Sample no. & Yield strength $(\mathrm{MPa})$ & Average of yield strength $(\mathrm{MPa})$ & Ultimate strength (MPa) & $\begin{array}{c}\text { Average of ultimate } \\
\text { strength }(\mathrm{MPa})\end{array}$ \\
\hline \multirow{3}{*}{ Steel beam } & 1 & 279.7 & \multirow{3}{*}{288.3} & 447.5 & \multirow{3}{*}{441.7} \\
\hline & 2 & 302.7 & & 440.8 & \\
\hline & 3 & 282.4 & & 436.8 & \\
\hline \multirow{3}{*}{ Rebar } & 1 & 485.0 & \multirow{3}{*}{468.3} & 635.0 & \multirow{3}{*}{630.0} \\
\hline & 2 & 485.0 & & 635.0 & \\
\hline & 3 & 435.0 & & 620.0 & \\
\hline
\end{tabular}

applied, the specimens were heated according to the standard ISO-834 temperature curve.

\section{Experimental Results and Discussion}

3.1. Experimental Observations and Failure Modes. Two fire tests were carried out, in which the specimens SCB-1 and SCB-2 were tested at the same time and the specimen SCB-3 was tested separately. The main structural responses and failure modes of the three specimens are given below.

3.1.1. $S C B$-1. After being heated for 8 minutes, a bursting sound occurred from the superposed slabs. At 10 minutes of the fire test, an overall vibration of the composite beam, accompanied by a loud sound, was observed. At 27 minutes, water spots began to appear near the ends of the superposed slabs. Along with the temperature rise, the water spots continued to grow, forming a large scope water bay shown in Figure 6(a). At 52 minutes, the deflection at the midspan had been largely developed. The scope of the water bay gradually shrunk with the increased temperature. At 75 minutes, the heating process was terminated as severe out-of-plane buckling of the slab occurred.

The tested specimen was passively cooled to a room temperature condition, during which no abnormal incident was observed. The main failure characteristics were as follows. (1) A large crack, as shown in Figure 6(b), on the top surface of SCB-1 extended from one end of the composite beam toward its midspan with gradually narrowed crack width. The maximum width of the crack was about $1 \mathrm{~mm}$. (2) Vertical cracks were developed on the two longitudinal sides of the concrete slab and mainly concentrated above the superposing interface. Moreover, they were also observed in the postcast joint areas. (3) Vertical cracks appeared on the two transverse sides of the concrete slab and they were mainly distributed above the steel beam. (4) No cracks were 


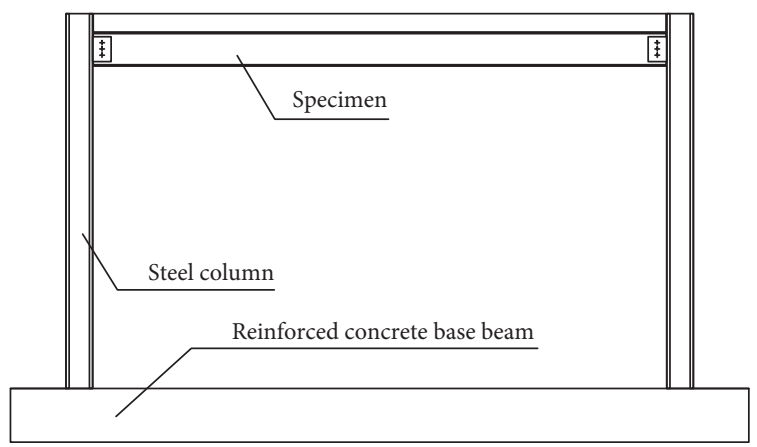

(a)

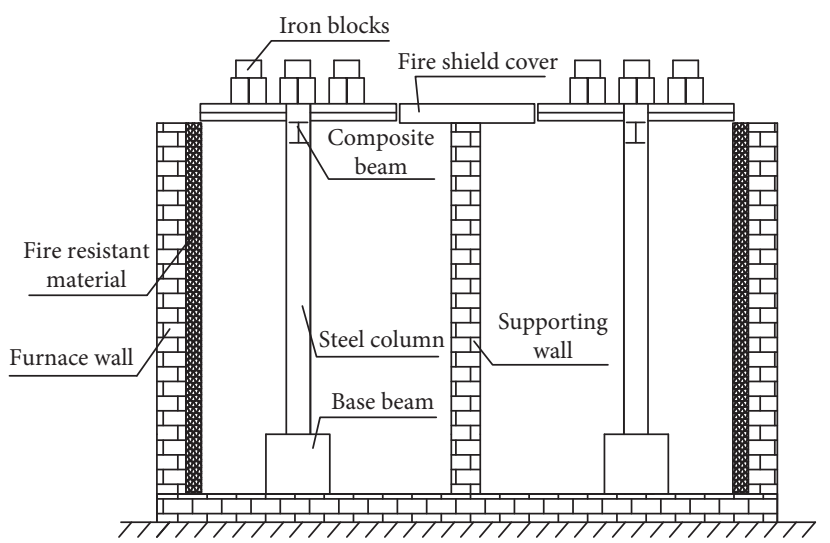

(c)

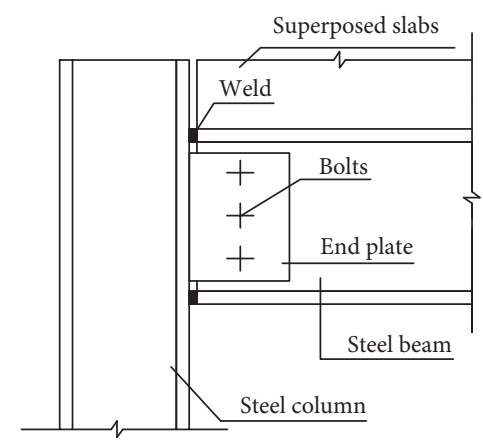

(b)

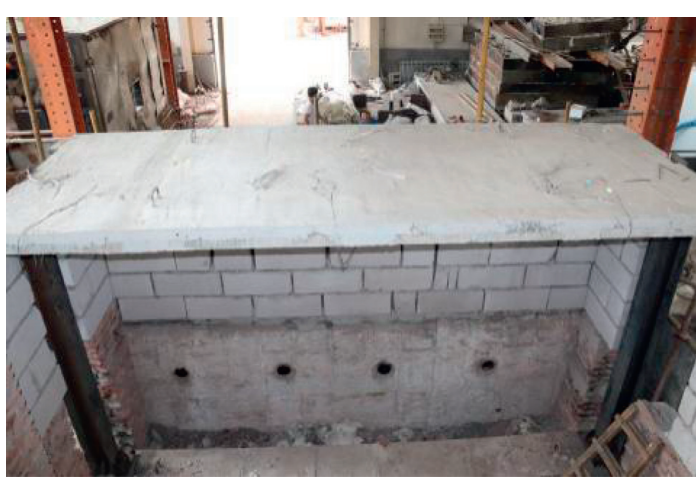

(d)

Figure 2: Experimental program: (a) specimen restraining scheme, (b) details of restraints, (c) test setup, and (d) composite beam specimen.

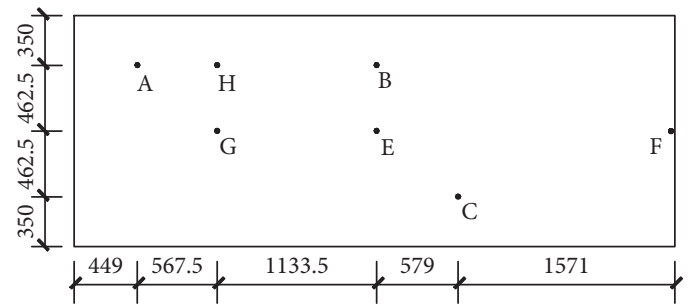

(a)

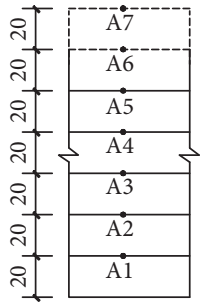

(b)

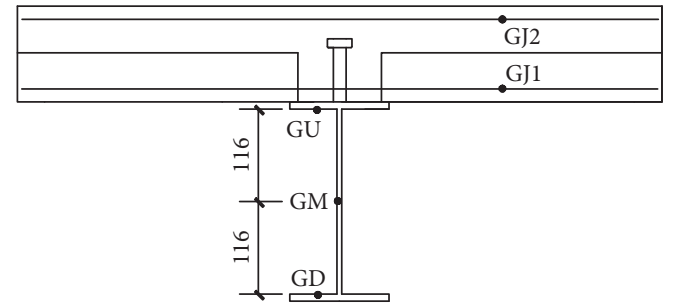

(c)

FiguRE 3: Temperature measurement positions: (a) plan arrangement, (b) measurement positions for concrete, and (c) measurement positions for rebars and steel beams.

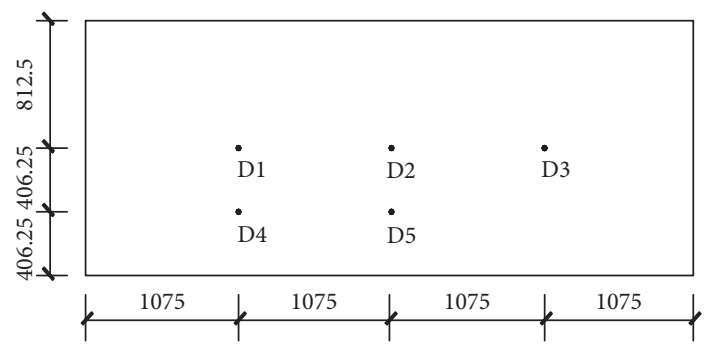

FIgURE 4: Arrangement of LVDTs.

observed on the bottom surface of the concrete slab yet local bursts happened (Figure 6(c)). (5) At the end restraints, the weld joint between the top flange of the steel beam and the steel column was torn, which might be the source of the loud sound during the test. An overall torsional deformation of the steel beam was also observed.

3.1.2. SCB-2. When the SCB-2 was heated for 13 minutes, the composite beam generated an overall vibration, accompanied by a loud sound. Another loud sound was made again at 25 minutes. Water spots (Figure $7(\mathrm{a})$ ) emerged at the ends of the superposed slabs at 27 minutes and became a large scope water bay given the rise of the temperature. At 45 minutes, an obvious out-of-plane instability of the composite beam was captured. Due to the evaporation, the water bay began to fade away. The test was stopped due to the 


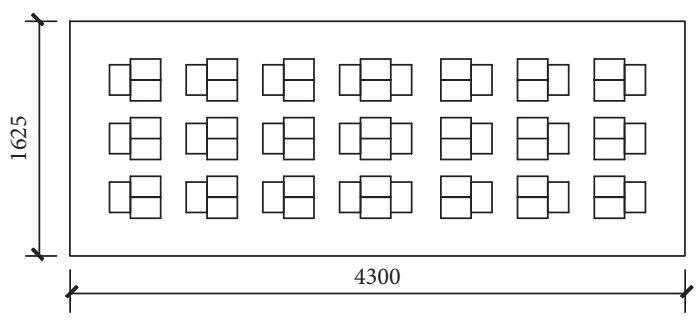

FIGURE 5: Layout of the iron blocks.

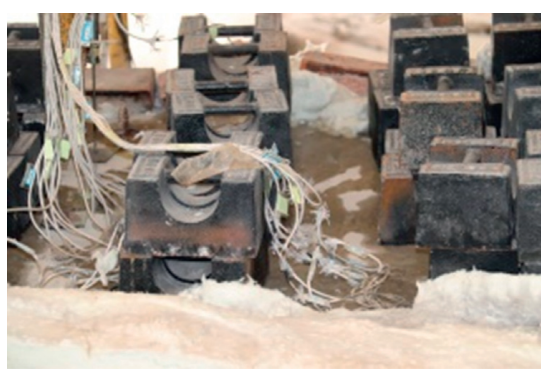

(a)

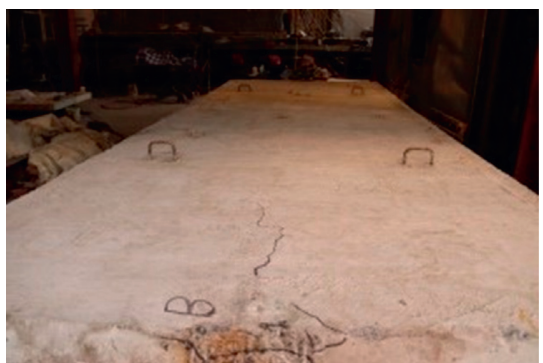

(b)

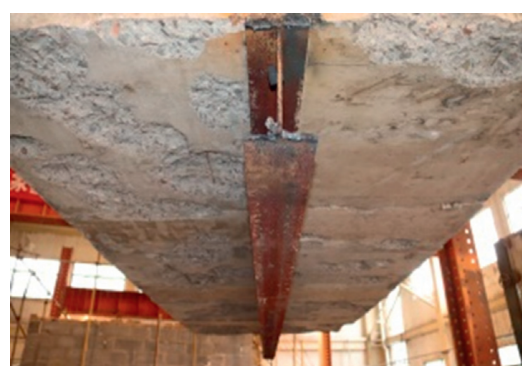

(c)

FIgURE 6: Failure modes of SCB-1: (a) water bay, (b) cracks on the top surface of the slab, and (c) local bursts on the bottom surface of the slab.

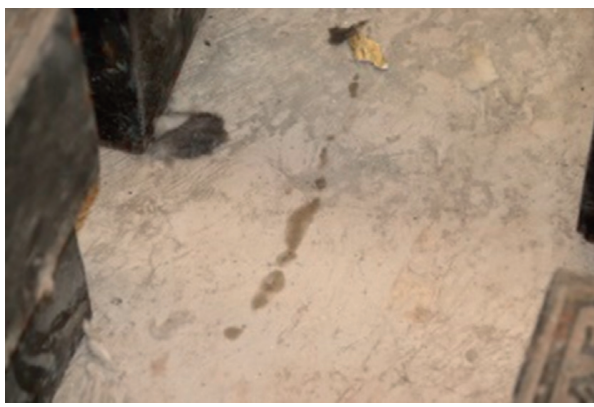

(a)

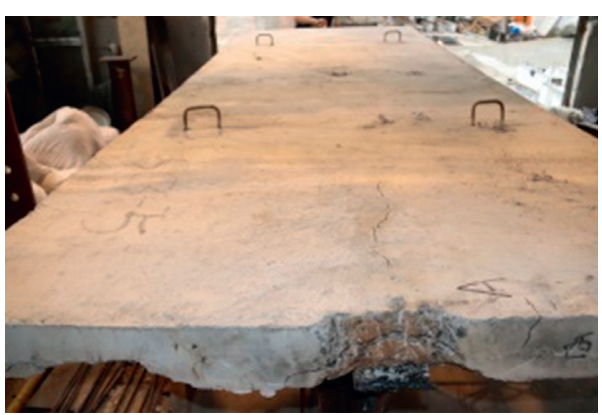

(c)

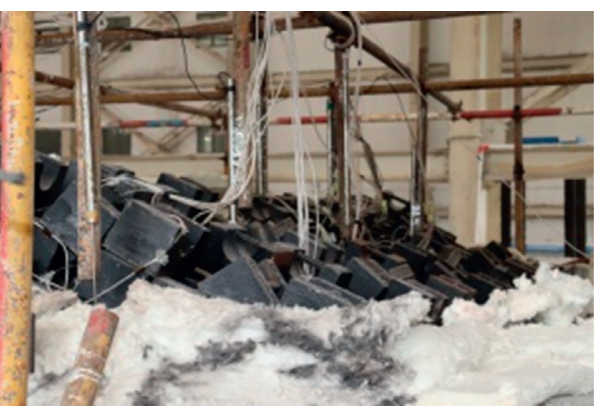

(b)

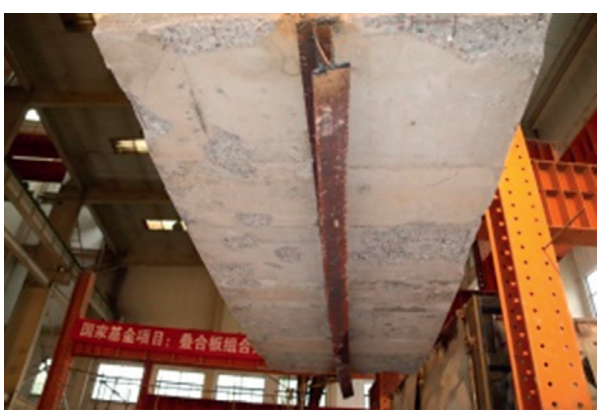

(d)

Figure 7: Failure modes of SCB-2: (a) water spots, (b) severe out-of-plane instability of the slab, (c) cracks on the top surface of the slab, and (d) local bursts on the bottom surface of the slab.

severe out-of-plane buckling of the slab which is shown in Figure 7(b).

Similar to the SCB-1, the failure modes of SCB-2 were examined after it was passively cooled to a room temperature condition. (1) The top surface cracks (Figure 7(c)) appeared from both ends of the slab and grew toward its midspan along the longitudinal direction. The same maximum crack width of $1 \mathrm{~mm}$ was also measured from the SCB- 2 specimen. 
(2) Similar distribution patterns of the vertical cracks were developed on both longitudinal and transverse side surfaces of the concrete slab while local bursts (Figure 7(d)) also took place on its bottom surface. (3) In contrast with SCB-1, the weld joint for both top and bottom flanges of the steel beam fractured and produced the loud sound.

3.1.3. SCB-3. The overall specimen vibrations, together with loud sounds, occurred twice after 9 and 12 minutes of the fire test. At 18 minutes, a noticeable vertical deflection (Figure $8(\mathrm{a})$ ) at the midspan of the specimen was observed. At 29 minutes, water spots were observed at both ends and midspan of the specimen, as shown in Figure 8(b). At 32 minutes, the out-of-plane buckling was generated in the tested specimen and increasingly aggravated, which ultimately stopped the test at 92 minutes.

Compared to the other two specimens, local concrete bursts (Figure 8(c)) also occurred on the bottom surface of the superposed slab, yet a relatively longer crack with a $1,205 \mathrm{~mm}$ length was produced on its top surface. Moreover, the weld joint for both top and bottom flanges fractured, which led to an overall distortion of the steel beam.

3.2. Temperature Field Analysis. The comparison of the actual furnace temperatures of the two tests and the ISO standard heating curve is shown in Figure 9(a), which shows that the trends of the furnace temperature change fairly followed the ISO standard. The rapid temperature rise also suggests that the fire flashover was well simulated. The nearly identical furnace temperature curves of the two tests indicate that a similar temperature distribution in the three specimens could be achieved. The test results of SCB-2 are given below and analysed to present a typical thermal response of composite beams with superposed slabs.

As shown in Figures 9(b) and 9(c), owing to the thermal inertia of concrete, the temperature of the composite beam flange decreased along the height of the superposed slab section. The highest temperature was achieved at the bottom of the superposed slab, whereas the lowest one was found at its top. The most drastic change of the temperature along the slab cross section was found in the region with a distance of $40 \mathrm{~mm}$ to the slab bottom. With respect to the cooling, the temperature at the slab bottom went down faster than the ones at other regions in the same slab section. Due to the variation of the temperature distribution, a temperature gradient was produced along the thickness of the superposed slab. As a result, temperature stresses were generated within the slab and led to a tension effect in its top region. Such tensile temperature stresses, with the assistance of the bending moment due to the applied load, created top surface cracks along the longitudinal direction. Note that measurement position A in Figure 9(b) and position B in Figure 9(c) were at the superposed slab and the postcast joint, respectively. It is shown that the temperature gradients at these two positions were almost identical, which indicates that the superposing interfaces between the precast slabs and postcast top layers were not broken. In relation to the reinforcing bars, their temperatures were basically consistent with the surrounding concrete. The considerable temperature differences between the top (GJ2) and the bottom (GJ1) bars were mainly attributed to their distances to the source of the heat.

Figure 9(d) depicts the temperature changes measured at three positions on the midspan section of the steel beam. Specifically, EU and ED denote the measuring points on the top and bottom flanges, respectively, whereas EM denotes the measuring point on the web. The trends of three temperature changes were approximately the same and the maximum temperature of the steel beam was as high as $682^{\circ} \mathrm{C}$. In the heating stage, the temperature of the top flange was lower than the other two positions as it was connected to the superposed concrete slab which absorbed a certain amount of the heat. In comparison, relatively less heat loss was caused on the web and the bottom flange of the steel beam as they were surrounded by hot air. In the cooling stage, the temperature of the bottom flange was lower than the ones of the other two positions. It is noted that the temperature of the concrete slab was higher than the one in the furnace due to its thermal inertia. Compared to the top flange and web, the bottom flange of the steel beam received less heat transfer.

The maximum temperatures of the steel beam and the concrete superposed slab were $682^{\circ} \mathrm{C}$ and $354^{\circ} \mathrm{C}$, respectively. Such a large temperature difference led to incompatible deformations developed in the steel beam and the concrete slab, which introduced restraints to the steel beam by the concrete slab.

3.3. Displacements of Specimens. The vertical displacement developments at selected position of three tested specimens are shown in Figure 10. Among these positions, D1, D3, and D4 were located at a distance of $1 / 4$ span to the transverse sides of the specimens, whereas D2 and D5 were located at the midspan. The downward displacements are considered positive in this study. During the test, composite beams with superposed slabs experienced a certain degree of out-ofplane buckling due to the torsion of the steel beams. As D4 and D5 were also located at a distance of $1 / 4$ specimen width to the longitudinal sides of the specimen (see Figure 4), they were greatly affected by such a torsional effect. For SCB-1, as these two positions were on the upward movement side of the torsional axis, their displacement values were smaller than the ones of corresponding positions D1 and D2 which were approximately on the torsional axis. For SCB-2, due to a more severe torsional effect, the displacements at D4 and D5 shift from positive to negative, which indicates that their directions were changed from downward to upward during the test. In contrast to SCB-1 and SCB-2, D4 and D5 of SCB3 were located on the downward movement side with respect to the torsional axis. As a result, larger displacement values were obtained when compared to D1 and D3.

The test data were collected until 287 minutes from the beginning of the SCB-1 test, in which a maximum displacement of $109.0 \mathrm{~mm}$ and a residual displacement of $79.6 \mathrm{~mm}$ were recorded, resulting in a deformation recovery ratio of $27.0 \%$. The maximum displacement and the 


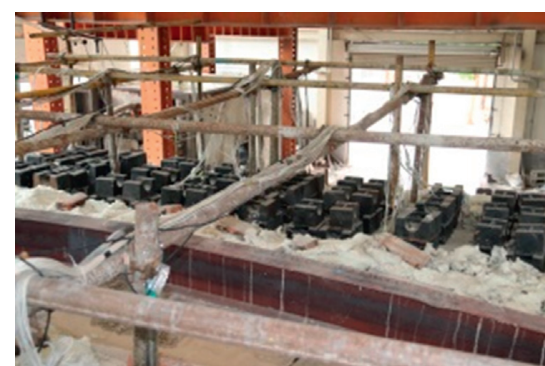

(a)

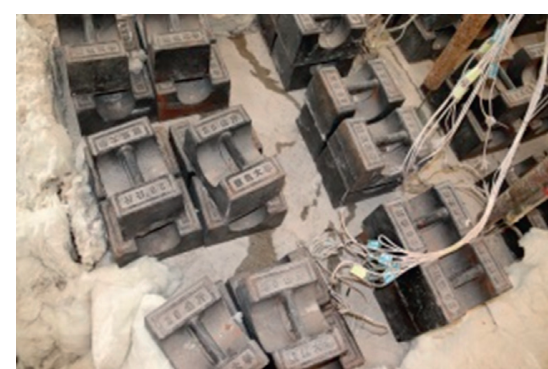

(b)

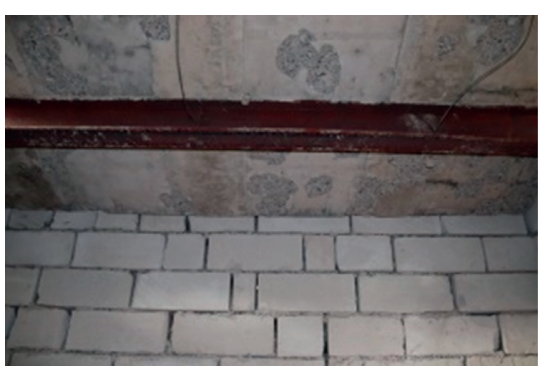

(c)

Figure 8: Failure modes of SCB-3: (a) vertical deflection, (b) water spots, and (c) local bursts on the bottom surface of the slab.

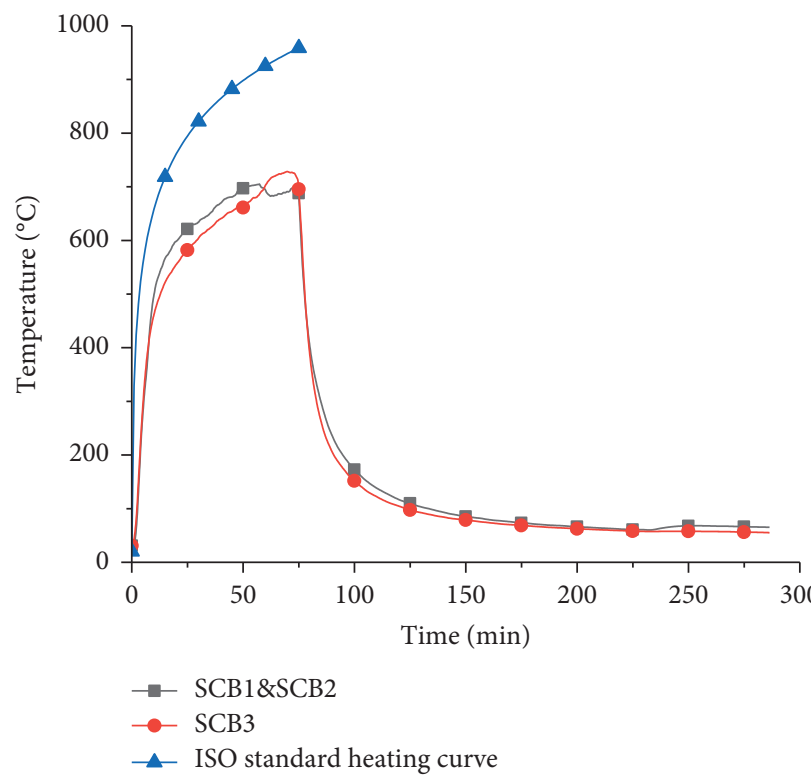

(a)

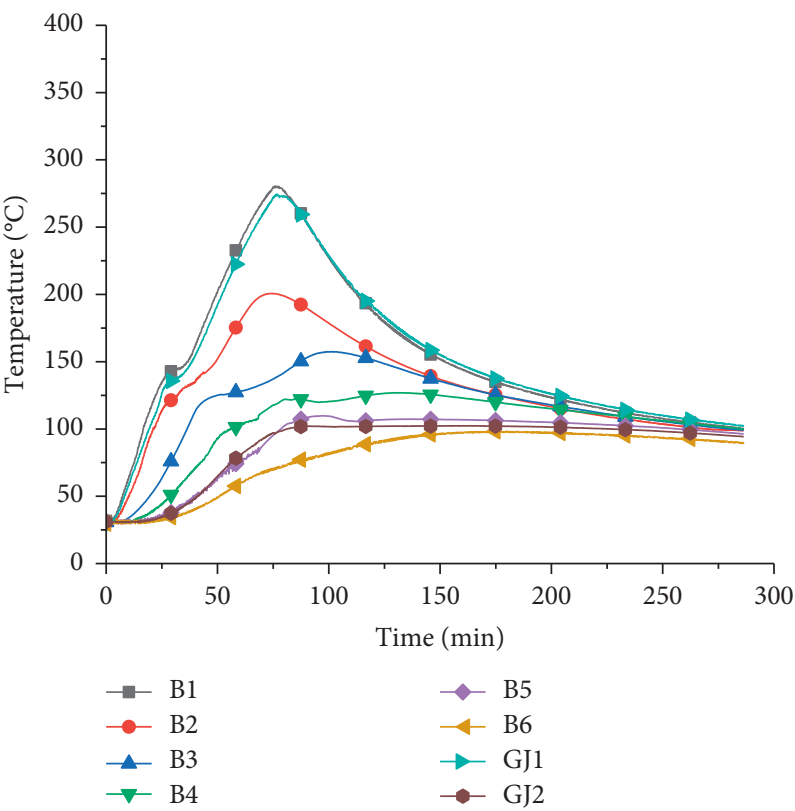

(c)

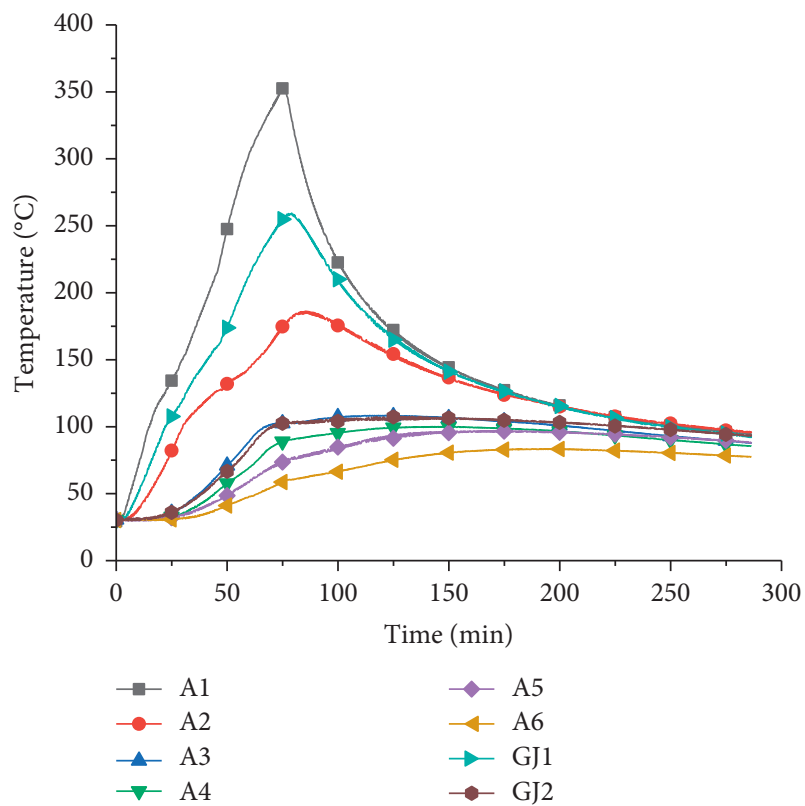

(b)

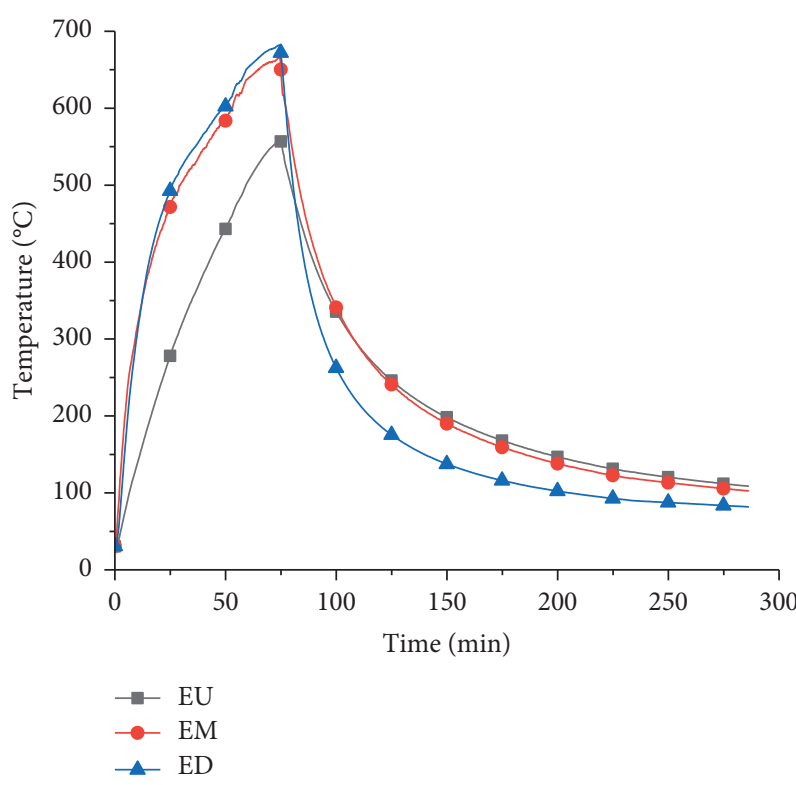

(d)

Figure 9: Temperature field analysis of SCB-2: (a) comparison of temperature curves, (b) temperature changes at position A, (c) temperature changes at position $\mathrm{B}$, and $(\mathrm{d})$ temperature changes of the steel beam. 


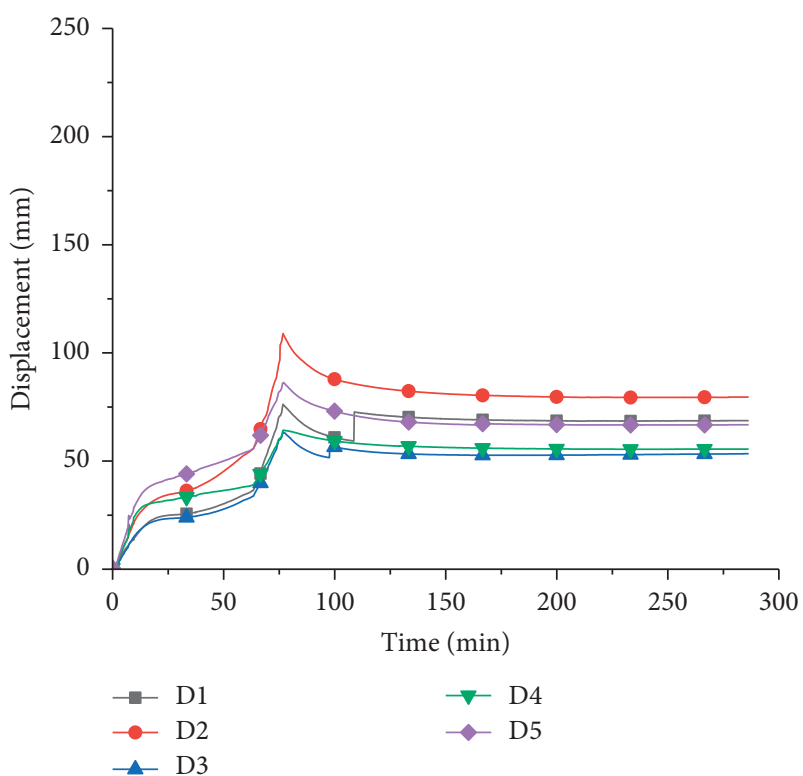

(a)

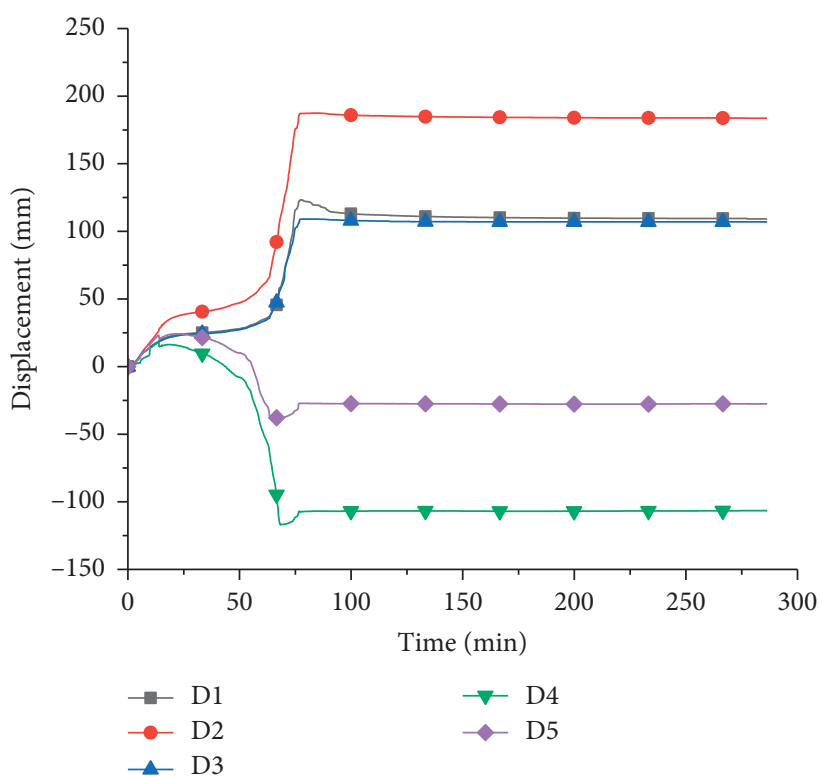

(b)

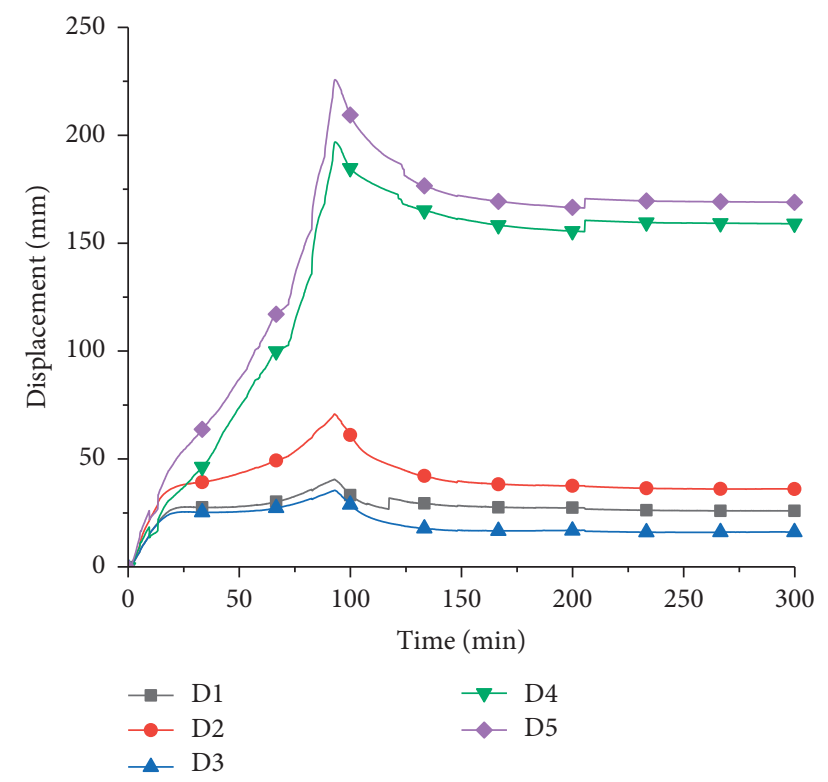

(c)

Figure 10: Displacement-time curves of (a) SCB-1, (b) SCB-2, and (c) SCB-3.

deformation recovery ratio of SCB-2 were not available due to its severe out-of-plane buckling failure. During the test period of 300 minutes for SCB-3, the maximum and residual displacements were found to be $70.8 \mathrm{~mm}$ and $36.0 \mathrm{~mm}$, respectively. Therefore, deformation recovery ratio of $49.1 \%$ was achieved, which was significantly larger than SCB-1. It is implied that a smaller spacing of shear studs would have a negative effect on the deformation recovery capacity of the superposed slabs.

The comparison of the displacement developments of SCB-1 and SCB-2 is presented in Figure 11(a). It is seen that the two specimens exhibited almost identical displacement increase patterns in the heating stage. Hence, the thickness of the postcast top layer has a negligible effect on the displacement development of the composite beams with superposed slabs. With a further increase of the temperature, the displacements of the SCB-2 grew rapidly due to the out-of-plane buckling.

Figure 11(b) depicts the comparison of the displacement developments of SCB-1 and SCB-3. Although their displacement development patterns were also found to be similar in the heating stage, the two specimens behaved differently in the cooling stage. Moreover, the displacement values of SCB-1 were higher than the corresponding ones of 


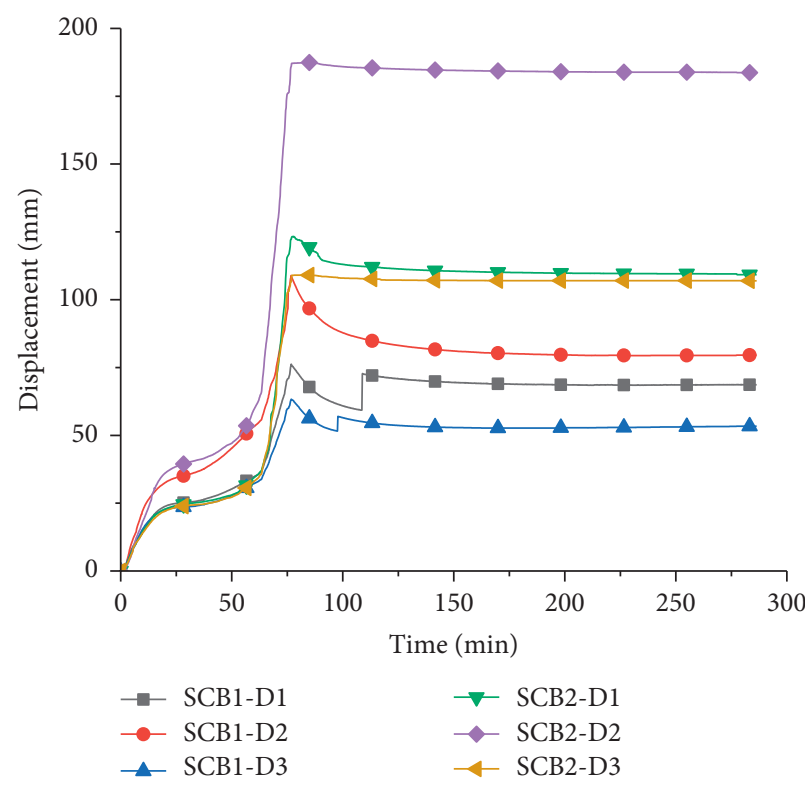

(a)

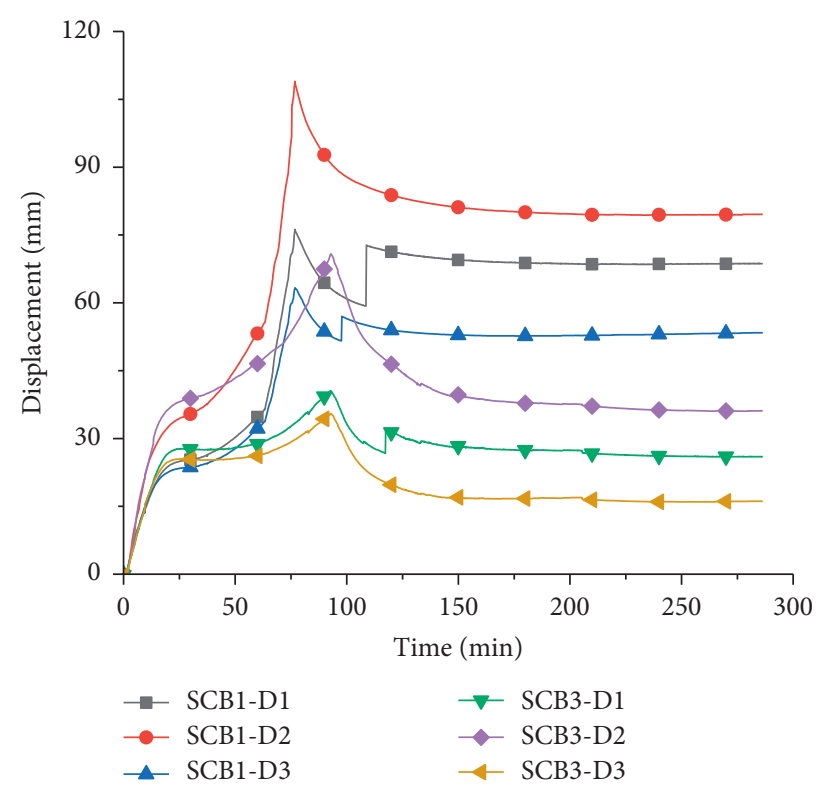

(b)

FIgURE 11: Comparisons of displacement developments of (a) SCB-1 and SCB-2 and (b) SCB-1 and SCB-3.

SCB-3. It was largely because more shear studs with a smaller spacing were able to transfer more heat to the superposed slab, which further weakened its material and enlarged the overall deformation.

\section{Numerical Simulation}

Finite element models of the composite beams were created using a numerical analysis software ABAQUS. Sequenced thermomechanical coupling analysis was performed to simulate the fire tests and the temperature field and displacement results were compared against the experimental ones.

4.1. Material Properties. The parameters of specific heat, conduction, and density of concrete and steel materials at high temperatures were determined according to an existing research [16] and relevant standards [17, 18]. The measured furnace temperature-time curve was employed for the temperature field simulation. Absolute zero degree was set as $-273^{\circ} \mathrm{C}$, and the Stefan-Boltzmann constant was set as $5.67 \times 10^{-8}$. The comprehensive radiation coefficient of the fire receiving surface was set as $0.5 \mathrm{~W} /\left(\mathrm{m}^{2} \cdot{ }^{\circ} \mathrm{C}\right)$, and the convective heat transfer coefficient was set as $40 \mathrm{~W} /\left(\mathrm{m}^{2} \cdot{ }^{\circ} \mathrm{C}\right)$.

The strengths, elastic moduli, and stress-strain relationships of concrete and steel at high temperature were determined according to the existing studies [17-21].

4.2. Elements and Coupling Settings. Except for the reinforcement which was modelled using 2-node truss elements, all other components were created using 8-node solid elements.
In the temperature field simulation, the interactions between each part of the tested specimens were defined as "Ties" so that the heat can be transferred between different parts. In the thermomechanical coupling analysis, the reinforcing bars were "Embedded" into the concrete superposed slabs with other settings unchanged.

4.3. Load and Boundary Conditions. The temperature field simulation was conducted firstly, after which the loads and boundary conditions were applied. The stresses of the model in the temperature field simulation were introduced as the initial stresses for the followed thermomechanical coupling analysis. The bottom ends of the steel columns were fully fixed and a UDL of $3.5 \mathrm{kN} / \mathrm{m}^{2}$ was applied to the top surfaces of the superposed slab models. The numerical model of a typical composite beam with superposed slabs specimen is shown in Figure 12.

4.4. Numerical Results. As the temperature distributions of three specimens were similar, only the simulation results of SCB-2 are presented here for illustrating a typical thermal response. The temperature contours of SCB-2 at the beginning of heating and after 75 minutes are shown in Figure 13 while the simulated temperature developments in the specimen are compared against the corresponding test results in Figure 14. It is seen that simulated temperature distributions agree well with the test results.

The displacement contours of the three tested specimens at the end of the heating stage are shown in Figure 15, while the simulated displacement developments at selected positions are compared against the corresponding test results in Figure 16. An accurate prediction 


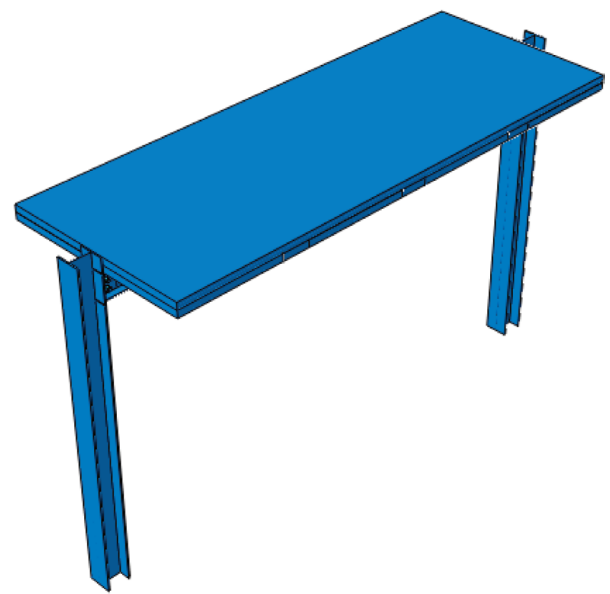

Figure 12: Numerical model of the composite beam specimens.
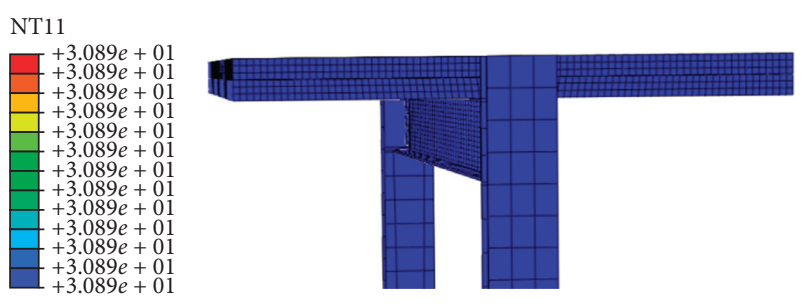

(a)
NT11
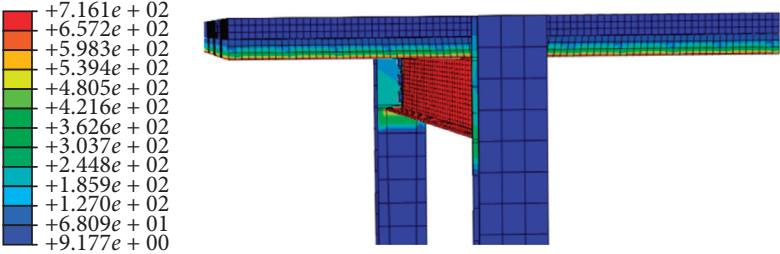

(b)

Figure 13: Temperature contours of SCB-2 (a) at $0 \mathrm{~min}$ and (b) at $75 \mathrm{~min}$.

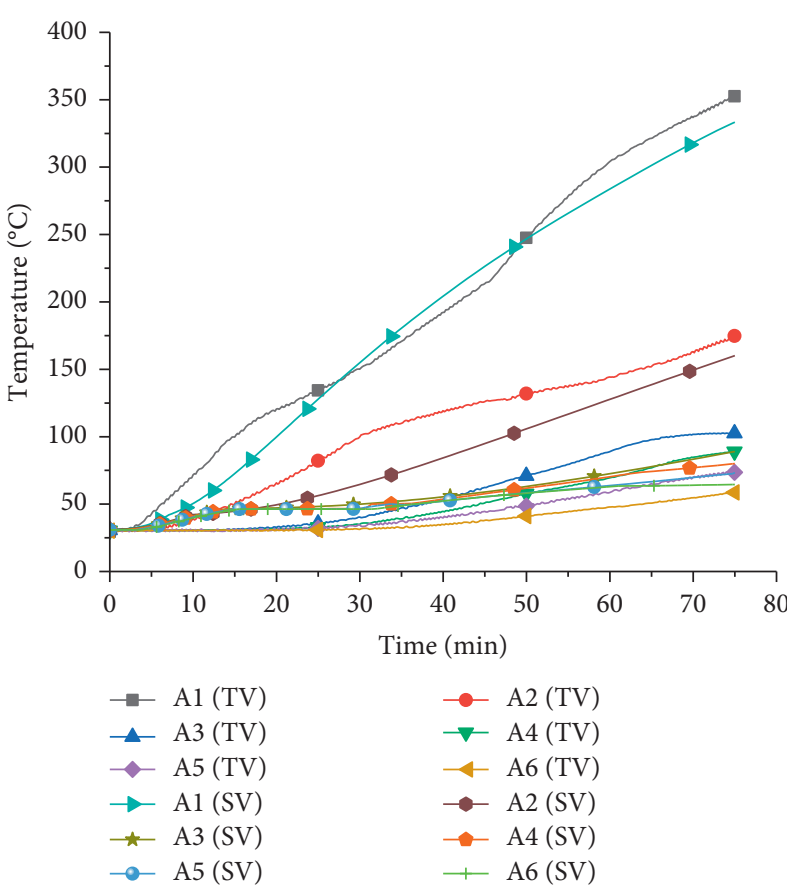

(a)

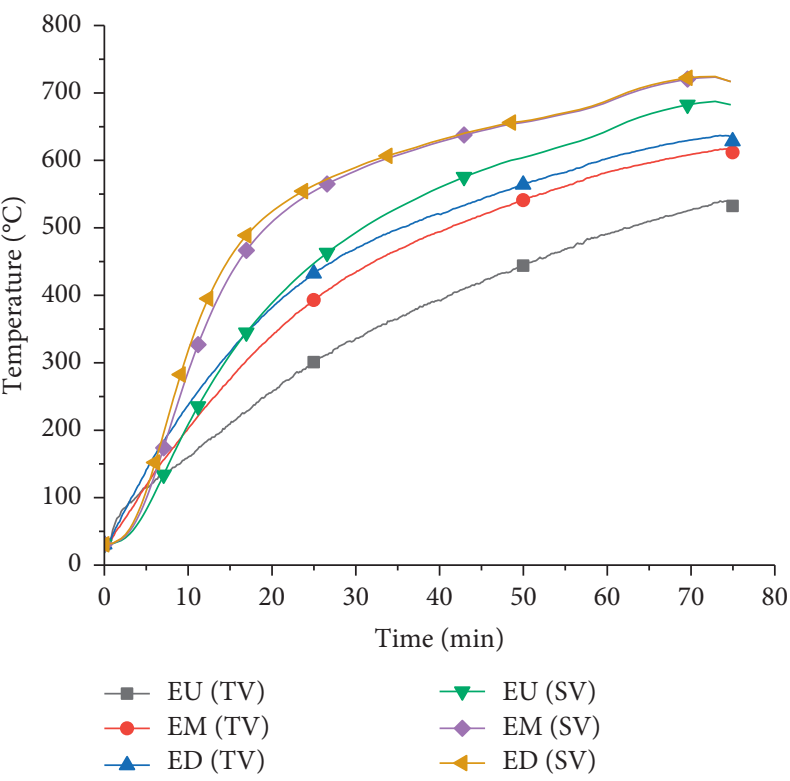

(b)

FIGURE 14: Comparison of temperature changes in SCB-2 for (a) concrete slab and (b) steel beam (note: TV=tested value and $\mathrm{SV}=$ simulated value; the same applies hereafter). 

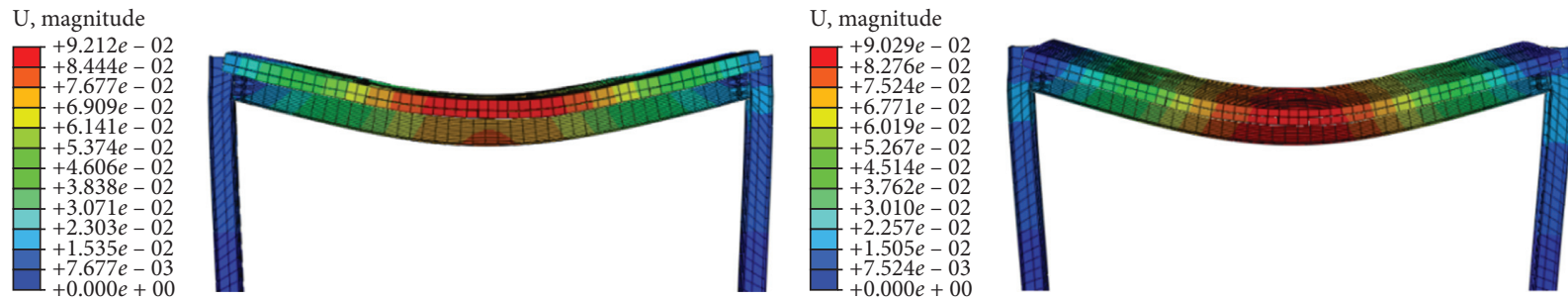

(a)

(b)

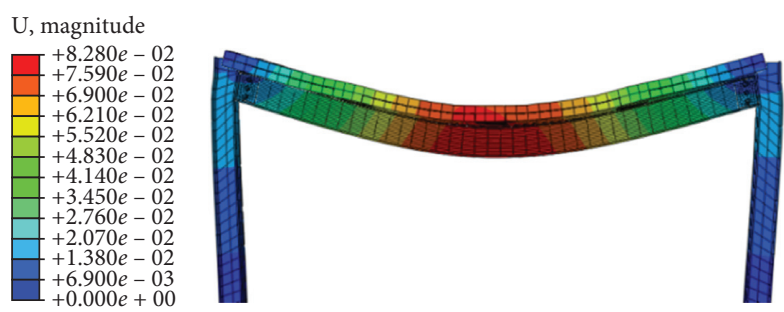

(c)

FIgURe 15: Displacement contours of three tested specimens: (a) SCB-1, (b) SCB-2, and SCB-3 (units are in m).

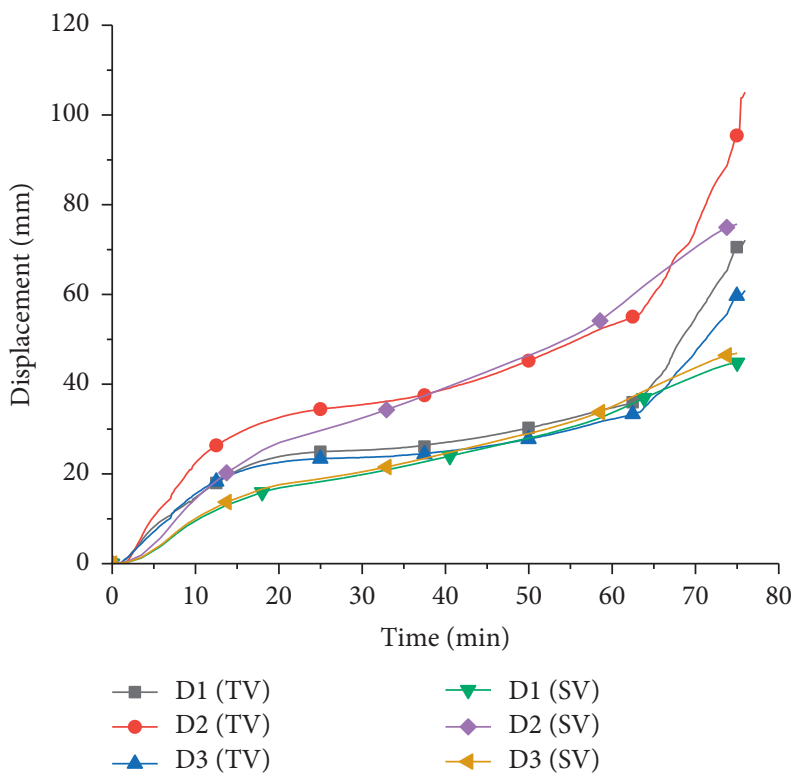

(a)

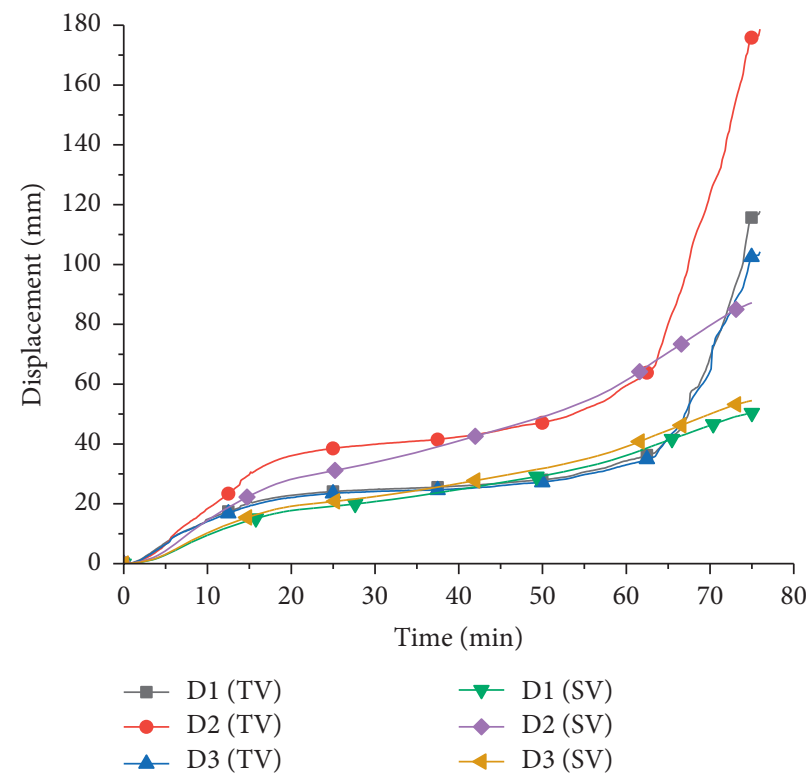

(b)

FIgURE 16: Continued. 


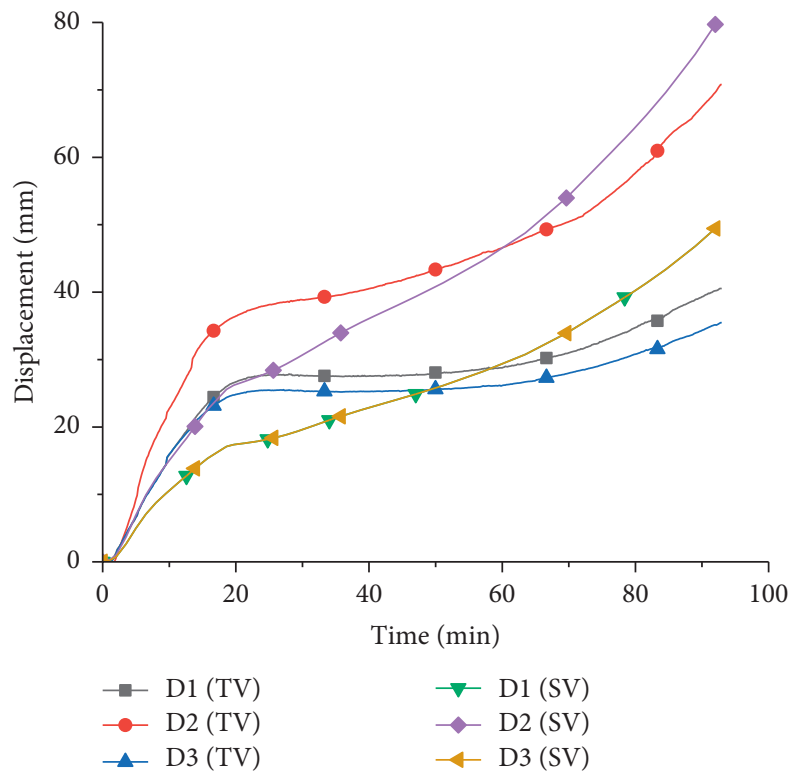

(c)

FIGURE 16: Comparison of displacement developments of three tested specimens: (a) SCB-1, (b) SCB-2, and (c) SCB-3.

of the overall displacement developments was achieved by the numerical models.

\section{Conclusion}

To investigate the fire resistance of composite beams with restrained superposed slabs, three specimens were tested. Through further temperature field and displacement analyses and numerical simulations, the following conclusions were obtained.

(1) In the heating stage, the temperature of the concrete superposed slabs decreased long their heights from the bottom. The most drastic change of the temperature along the slab cross section was the region with a distance of $40 \mathrm{~mm}$ to the slab bottom. The superposed concrete slabs could impose restraints to the steel beams due to their incompatible deformations.

(2) Cracks were developed along the longitudinal direction on the top surfaces of the specimens due to the temperature stresses and the applied load. The superposing interfaces between the precast slabs and postcast top layers were not broken during the tests yet local bursts occurred on the bottom surfaces of the precast slabs.

(3) The composite beams with restrained superposed slabs have an ability to recover a certain level of deformations after cooling.

(4) With restraints, the spacing of shear studs could have a significant effect on the fire resistance of composite beams, especially for their deformation recovery capacities. In contrast, the effect of the thickness of the postcast top layers was negligible.
(5) After simulating the temperature field and deformation behaviours of the specimens, the numerical results were found to agree well with the experiment data, which validated the developed numerical model.

\section{Data Availability}

The data used to support the study findings are available from the corresponding author upon request.

\section{Conflicts of Interest}

The author declares that there are no conflicts of interest regarding the publication of this paper.

\section{Acknowledgments}

The research described here received financial support from the National Natural Science Foundation of China (Project no. 51878398).

\section{References}

[1] T. Lennon and D. Moore, "Client report: results and observations from full-scale fire test at BRE Cardington," Client report no. 215-741, Building Research Establishment, London, UK, 2004.

[2] B. R. Kirby, The Behavior of a Multi-Storey Steel Framed Building Subjected to Fire Attack: Experimental Data, British Steel, London, UK, 1998.

[3] O. Mirza and B. Uy, "Behaviour of headed stud shear connectors for composite steel-concrete beams at elevated temperatures," Journal of Constructional Steel Research, vol. 65, no. 3, pp. 662-674, 2009.

[4] J. H. Han, W. R. Cheng, Z. D. Xu et al., "Experimental study on the behaviors of profiled steel sheeting-concrete composite 
slabs on fire," Industrial Construction, vol. 36, no. 3, pp. 87-90, 2006, in Chinese.

[5] S. C. Jiang, G. Q. Li, G. B. Lou et al., "Numerical approach of behavior of steel-concrete composite slabs subjected to fire," Journal of Building Structures, vol. 25, no. 3, pp. 38-44, 2004, in Chinese.

[6] Z. H. Xu, Z. D. Lu, and L. G. Wang, "Nonlinear analysis of fire resistance of composite deck slabs," Journal of Building Structures, vol. 23, no. 5, pp. 73-83, 2002, in Chinese.

[7] S. G. Fan, Z. N. Li, H. Z. Wei et al., "Experimental study on membrane effect of steel deck concrete composite slabs on fire," Journal of Disaster Prevention and Mitigation Engineering, vol. 35, no. 1, pp. 44-50, 2015, in Chinese.

[8] Y. Z. Wang, Behavior and Design of Composite Beam in Fire with Considering Global Structure Effect, Tongji University, Shanghai, China, 2006.

[9] H. Y. Zhou, G. Q. Li, and Y. Z. Wang, "Analysis of two factors influencing the fire resistance of composite beams," Progress in Steel Building Structures, vol. 8, no. 5, pp. 40-45, 2006, in Chinese.

[10] J. L. Lyu, Y. L. Dong, and Z. N. Yang, "Experimental study on the deformation of a two-span steel beam in a structural system subjected to fire," Engineering Mechanics, vol. 29, no. 3, pp. 110-114, 2012.

[11] J. L. Lyu, Y. L. Dong, and Z. N. Yang, "Deformation investigation of single-span composite beams subjected to fire," Journal of Harbin Institute of Technology, vol. 43, no. 8, pp. 16-20, 2011, in Chinese.

[12] J. L. Lyu, Y. L. Dong, and Z. N. Yang, "Experimental and analytical studies on performance of edge beams of steel framed building subjected to fire," Journal of Building Structures, vol. 32, no. 9, pp. 92-98, 2011, in Chinese.

[13] J. L. Lyu, Study on Fire Resistance of Beam and Column in the Overall Steel Frame, Harbin Institute of Technology, Harbin, China, 2013.

[14] China Architecture and Building Press, Standard for Test Method of Mechanical Properties on Ordinary concrete:GB/ T50081 - 200, China Architecture and Building Press, Beijing, China, 2002.

[15] Standards Press of China, Materials-Tensile Testing-Part 1: Method of Test at Room Temperature: GB/T228. 1-2010, Standards Press of China, Beijing, China, 2010.

[16] T. T. Lie and E. M. A. Denham, "Factors affecting the fire resistance of circular hollow steel columns filled with barreinforced concrete," NRC-CNRC internal report no. 651, NRC-CNRC, Ottawa. Canada, 1993.

[17] Europe Committee for Standardization, ENV1993-1-2, Eurocode 3, Design of Steel Structures, Part 1.2: Structures Fire Design, Europe Committee for Standardization, Brussels, Belgium, 1993.

[18] EN 1994-1-2, Eurocode 4: Design of Composite Steel and Concrete Structures. Part 1-2: General Rules-Structural Fire Design, British Standards Institution, London, UK, 2004.

[19] Z. H. Guo and W. Li, Summary of Experimental Research on Heat Resistance Mechanical Properties of Concrete, Department of Civil Engineering, Tsinghua University, Beijing, China, 1991.

[20] H. D. Li, Experimental Research on Reinforced Concrete Compression-Bending Members under High Temperature, Tsinghua University, Beijing, China, 1994.

[21] China Architecture and Building Press, Code for Design of Concrete Structures: GB 50010-2002, China Architecture \& Building Press, Beijing, China, 2002. 